\title{
Point transect sampling of deadwood: a comparison with well-established sampling techniques for the estimation of volume and carbon storage in managed forests
}

\author{
Tim Ritter · Joachim Saborowski
}

Received: 21 November 2011/Revised: 9 May 2012/Accepted: 25 May 2012/Published online: 30 June 2012

(C) The Author(s) 2012. This article is published with open access at Springerlink.com

\begin{abstract}
In managed forests, the occurrence of deadwood (DW) can be regarded as a stochastically rare event with strong clumping and high local variability (Meyer in Forstwissenschaftliches Centralblatt 118:167-180, 1999). Traditional sampling techniques, such as Fixed Area Sampling, Angle Count Sampling and Line Intersect Sampling, do not regard this fact and may be inefficient for surveys of DW, because of limited search areas. A sampling technique that should remedy this shortcoming is Point Transect Sampling (Buckland et al. in Introduction to distance sampling: estimating abundance of biological populations. Oxford University Press, Oxford, 2001; Advanced distance sampling: estimating abundance of biological populations. Oxford University Press, Oxford, 2004), where as a matter of principle, all objects that are sighted from a fixed location are counted. We compare Point Transect Sampling with the other well-established sampling approaches for the estimation of volume, necromass and carbon storage in terms of precision and sampling effort. It is shown that Point Transect Sampling is the superior method for sampling standing DW regarding
\end{abstract}

Communicated by G. Kaendler.

T. Ritter $(\bowtie) \cdot$ J. Saborowski

Department Ecoinformatics, Biometrics and Forest Growth, Georg-August-Universität, Büsgenweg 4, 37077 Göttingen,

Germany

e-mail: tritter@gwdg.de

J. Saborowski

Department Ecosystem Modelling, Georg-August-Universität,

Büsgenweg 4, 37077 Göttingen, Germany efficiency, whereas for sampling downed DW, it is clearly outperformed by Line Intersect Sampling.

Keywords Deadwood - Woody debris · Distance sampling · Point transect sampling · Carbon sequestration · Carbon storage

\section{Introduction}

Deadwood (DW) is typically defined as "all non-living woody biomass not contained in the litter, either standing, lying on the ground, or in the soil" (FAO 2006, p. 172). However, in this paper, we only regard above ground DW.

Deadwood is an important component of many ecosystems, and it is abundant in many forest ecosystems and forms major structural features with many crucial ecological functions (Harmon et al. 1986). DW plays an important role for (1) Biodiversity, (2) Soil Protection and (3) Carbon sequestration.

1. Depending on cited literature, in Central Europe about $20-50 \%$ of all forest-dwelling species depend on different types of DW (Schaber-Schoor 2008).

2. DW enhances litter-dwelling detritivores, which impact nutrient cycling by diverting fluxes and changing the availability of macronutrients, such as phosphorus $(\mathrm{P})$, potassium $(\mathrm{K})$, calcium $(\mathrm{Ca})$ and magnesium $(\mathrm{Mg})$. Accumulation of DW on the forest floor locally improves soil quality and decreases the risk of tree damage caused by acidification (Kappes et al. 2007).

3. DW provides a midterm carbon (C) storage site (20-40 a). DW also is a potential for long-term $\mathrm{C}$ sequestration in the soil: During decomposition, $\mathrm{C}$ can be 
transferred to the atmosphere (in the form of $\mathrm{CO}_{2}$ ) or it can be added to $\mathrm{C}$ stocks in the soil (Kahl 2008; Kopra and Fyles 2005).

In Central European forest reserves, the mean volume of DW is about $130-150 \mathrm{~m}^{3} \mathrm{ha}^{-1}$ (Schaber-Schoor 2008; Christensen et al. 2005). In contrast, in Germany, only $11.5 \mathrm{~m}^{3} \mathrm{ha}^{-1}$ can be observed on an average in managed forests (Polley 2005). This seems problematic, because a critical decrease of species richness can be observed below 30-60 $\mathrm{m}^{3} \mathrm{ha}^{-1}$ (Schaber-Schoor 2008; Bütler and Schlaepfer 2004). Consequently, several Federal German States have established management concepts for DW. For instance, Bavaria aspires to have $20-40 \mathrm{~m}^{3} \mathrm{ha}^{-1}$, depending on stand type and age (Neft 2006).

The problem has also been recognized at the international political level by the 4th Ministerial Conference on the Protection of Forests in Europe (MCPFE 2003). Within the MCPFE process, a set of Pan-European Criteria and Indicators for Sustainable Forest Management has been developed (Schuck et al. 2004). Criterion 4.5 ("Volume of standing dead wood and of lying dead wood on forest and other wooded land classified by forest type") addresses DW volume (MCPFE 2002). Consequently, 21 European Countries have included dead wood sampling in their national forest inventories (Rondeux and Sanchez 2010).

Worldwide 30 countries inventory dead wood. These countries include over a third of the world's forestland. Almost all of these countries use Fixed Area Sampling for standing DW, for downed DW $63 \%$ of the countries use Fixed Area Sampling and $19 \%$ use Line Intersect Sampling (Woodall et al. 2009a, b).

Given these facts, there obviously is a need for effective sampling techniques for monitoring DW volume and carbon stock in managed forests, which can be integrated in existing forest inventories.

\section{Materials and methods}

Study area

Sample sites $(2,416$ ha in total) are located in Central Germany and cover the Forest Sub-Districts Reinhausen and Sattenhausen of the Lower-Saxony State Forest District Reinhausen $\left(51^{\circ} 30^{\prime} \mathrm{N}, 10^{\circ} 00^{\prime} \mathrm{E}\right)$. The area is hilly, with broad plateaus and steep edges. Elevation varies between 200 and $410 \mathrm{~m}$ above sea level.

Climate is subcontinental, with mean annual temperature of $8.0{ }^{\circ} \mathrm{C}$ and mean annual precipitation of $740 \mathrm{~mm}$. The soils are predominantly derived from Loess covered Upper and Middle Bunter and partially from Triassic Limestone. Soil types are predominantly cambisols, podzoluvisols, and luvisols and above limestone also rendzinas and calcaric cambisols. The potential natural forest vegetation can be assigned to different types of beech forests, mainly Hordelymo-Fagetum, Luzulo-Fagetum and GalioFagetum (Gauer and Aldinger 2005).

\section{Dataset}

The survey was carried out in 2009 and 2010, DW was sampled on 235 plots during the vegetative period and we refer to it as "summer campaign". The number of sample plots was limited to 235 due to funding limitations. In order to evaluate the dependence of the detection function (see Materials and methods: Volume estimation) on the foliation of the stand, 228 of the plots were resampled in defoliated state and we refer to it as "winter campaign".

The difference between the sample sizes of the two campaigns results from problems in recovering the sample plot marks (4 plots) and inaccessibility of areas after windbreak by the storm "Xynthia" (3 plots).

Sample plots were randomly selected from the phase two plots of the Lower-Saxony State Forest Inventory, which is carried out as two-phase sampling for stratification (Saborowski et al. 2010). However, in this study, we simply treat the sample plots as a complete random sample, because our goal is to compare the efficiency of the different sampling methods rather than producing volume estimations for the study area.

We differentiated between standing and downed DW. As standing DW (SDW), we considered every snag or stump with a diameter in $1.3 \mathrm{~m}$ height $(\mathrm{DBH})$ of $7 \mathrm{~cm}$ or more. As downed DW or Coarse Woody Debris (CWD), we considered every piece of DW lying on the ground, with a length of $1.3 \mathrm{~m}$ or more and a maximum diameter of $15 \mathrm{~cm}$ or more.

\section{Software}

Data analysis was performed using SAS software, version 9.2 CC $^{1}$ and the software package $\mathrm{R}$, version 2.13 .0 ( $\mathrm{R}$ Development Core Team 2011). For the Point Transect Sampling analysis, we used the software Distance, Version 6.0 Release 2 (Thomas et al. 2010).

\section{Volume estimation}

For CWD, the volume of a single object was calculated as the product of cross-sectional area in the middle of the object (obtained by cross-calipering) and length of the object (Huber 1839).

\footnotetext{
${ }^{1}$ Copyright, SAS Institute Inc. SAS and all other SAS Institute Inc. product or service names are registered trademarks or trademarks of SAS Institute Inc., Cary, NC, USA.
} 
For SDW, the volume of a single object was calculated from $\mathrm{DBH}$ (obtained by cross-calipering) and height (measured with a ultrasonic hypsometer). We differentiated between complete snags and broken snags or stumps. For complete snags, the volume was calculated, using a formfactor of 0.5 , whereas for broken snags, it was calculated using the formula for a truncated cone, assuming a taper of $1 \mathrm{~cm} \mathrm{~m}^{-1}$.

\section{Fixed Area Sampling}

Fixed Area Sampling was carried out in a design of circular sample plots with $13 \mathrm{~m}$ radius on the surface, where all CWD and SDW was measured. The volume per area unit $(Y)$ was estimated as

$\widehat{Y}=\frac{1}{n} \sum_{i=1}^{n} \widehat{Y}_{i}=\frac{1}{n} \sum_{i=1}^{n} \frac{\sum_{j=1}^{m_{i}} V_{i j}}{a_{i}}$

where $n$ is the number of sample plots, $m_{i}$ is the number of objects within the $i$ th sample plot, $V_{i j}$ is the volume of the $j$ th object within the $i$ th sample plot and $a_{i}$ is the horizontal area of the sample plot.

\section{Line Intersect Sampling}

We used Line Intersect Sampling (Warren and Olsen 1964; Van Wagner 1968) for sampling CWD. The sampling design was largely along the lines of the third Swiss National Forest Inventory (Böhl and Brändli 2007). Beginning at the centre of the plot, three transects, each one with a length of $15 \mathrm{~m}$ on the surface, were laid out star-shaped [azimuth 0 gon, 130 gon, 270 gon $\left.\left(\widehat{=} 0^{\circ}, 117^{\circ}, 243^{\circ}\right)\right]$. The inclination angle of each transect was measured for slope correction, and the total horizontal transect length per plot $L_{i}$ was calculated as the sum of the horizontal lengths of the three transects. At the intersection point of every object $j$, with one of the intersects at plot $i$, two diameters $d_{i j 1}$ and $d_{i j 2}$ were obtained by crosscalipering. Furthermore, the inclination angle of that object $\alpha_{i j}$ was measured for inclination correction. The volume per area unit $(Y)$ was estimated as

$\widehat{Y}=\frac{1}{n} \sum_{i=1}^{n} \widehat{Y}_{i}=\frac{1}{n} \sum_{i=1}^{n} \frac{\pi^{2}}{8 L_{i}} \cdot \sum_{j=1}^{m_{i}}\left[\left(\frac{d_{i j 1}+d_{i j 2}}{2}\right)^{2} \cdot \frac{1}{\cos \left(\alpha_{i j}\right)}\right]$.

\section{Point Transect Sampling}

We used Point Transect Sampling (Buckland et al. 2001, 2004) for sampling CWD and SDW.

Please note that in order to keep in line with the other methods, we use a slightly different notation than Buckland et al. (2001): $n$ instead of $k$ for the number of points, $m$ instead of $n$ for the number of objects encountered and $Y$ instead of $D$ for the density (i.e. volume per area unit).

In a first step, we used Point Transect Sampling for the estimation of the object density $D_{s}$ from the number of objects $m$, the number of Point transects $n$ and the probability $\widehat{P}_{a}=\frac{2}{\omega^{2}} \cdot \int_{0}^{\omega} r \cdot \widehat{g}(r) \mathrm{d} r$ that a randomly chosen object is detected within a circle of radius $\omega$ and area $a$. The socalled detection function $g(r)$ is fitted to the frequency distribution of encountered objects at different distances $r$ and explains the detection probability at distance $r$. The Point Transect Sampling estimator according to Buckland et al. (2001) is

$\widehat{D_{s}}=\frac{m}{n \cdot \pi \omega^{2} \cdot \widehat{P}_{a}}$

or equivalently

$\widehat{D_{s}}=\frac{m \cdot \hat{h}(0)}{2 \pi n}$

where $\hat{h}(0)=1 / \int_{0}^{\omega} r \cdot \widehat{g}(r) \mathrm{d} r$ is actually the slope of the probability density function $f(r)$ evaluated at $r=0$ (Buckland et al. 2001, Chap. 3.1.3).

Based on the minimum Akaike information criterion (AIC), the best model for estimating $g(r)$ was selected from all possible combinations of three key functions and two series expansions of up to 5th order (Buckland et al. 2001, Chap. 2.4).

Key functions are:

1. Uniform: $\widehat{g}(r)=1 / \omega$

2. Half-normal: $\widehat{g}(r)=\mathrm{e}^{\frac{-r^{2}}{2 \sigma^{2}}}$

3. Hazard rate: $\widehat{g}(r)=1-\mathrm{e}^{-\left(\frac{r}{\sigma}\right)^{-b}}$

Series expansions

1. Cosine: $\sum_{k=2}^{q} a_{k} \cos \left(\frac{k \pi r}{\omega}\right)$

2. Simple polynominal: $\sum_{k=2}^{q} a_{k}\left(\frac{r}{\omega}\right)^{2 k}$

The negative exponential key function $\widehat{g}(r)=\mathrm{e}^{-r / \sigma}$ was excluded from model selection, because it showed a very strong sensitivity regarding the choice of the truncation point $\omega$.

For the winter sampling campaign of CWD, a binary covariate (snow), indicating the presence/absence of a closed snow coverage, was included in the model. The scale parameter $\sigma$ was estimated separately for the two values of snow, so that the influence of the snow coverage on the detection probability could be modelled.

The basic idea for estimating $Y$ is to interpret every object of DW as a cluster of volume units with cluster size $s_{i}$, so that $Y$ can be estimated as the product of $\widehat{D_{s}}$ and an estimation of the expected cluster size $E(s)$ (Buckland et al. 2001, Chap. 3.5): 
$\widehat{Y}=\widehat{E}(s) \cdot m \cdot\left(n \cdot 2 \pi \cdot \int_{0}^{\omega} r g(r) \mathrm{d} r\right)^{-1}$

$E(s)$ can be estimated by the sample mean of all detected cluster sizes. However, the detection probability of large clusters may be higher than that of small clusters. Therefore, the expected size of detected clusters $E_{d}(s)$ can be modelled as a function of the distance-dependent detection probability. Because the cluster size is highly variable, we used a log-transformation $z_{i}=\log _{e}\left(s_{i}\right)$ (Buckland et al. 2001, Chap. 3.5.4), so that the expected (transformed) size of detected objects is estimated by:

$\widehat{E_{d}}(z \mid r)=a+b \cdot \hat{g}(r)$

$E(z)$ can then be estimated as $\widehat{E_{d}}(z \mid r=0)=a+b$, because the detection probability at distance $r=0$ is 1 for all cluster sizes. This yields (Buckland et al. 2001, Eq. 3.64):

$\widehat{E}(s)=\mathrm{e}^{a+b+\widehat{\operatorname{var}}(\hat{z}) / 2}$

where (Buckland et al. 2001, Eq. 3.65)

$\widehat{\operatorname{var}}(\hat{z})=\left(1+\frac{1}{m}+\frac{(1-\bar{g})^{2}}{\sum_{i=1}^{m}\left(\hat{g}\left(r_{i}\right)-\bar{g}\right)^{2}}\right) \cdot \widehat{\sigma}^{2}$

$\widehat{\sigma}^{2}$ is the residual mean square of model (Eq. 6) and $\bar{g}=\sum_{i=1}^{m} \hat{g}\left(r_{i}\right) / m$.

Whenever the model (Eq. 6) produced a significant slope $(p<0.05)$, we used this so-called size bias regression, otherwise we used the sample mean of the detected clusters.

Deadwood volume per area unit $(Y)$ is then estimated by

$\widehat{Y}=\widehat{E}(s) \cdot \widehat{D_{s}}$

\section{Angle Count Sampling}

We simulated Angle Count Sampling (Bitterlich 1952, 1984) from the Point Transect Sampling data, with three different counting angles $\alpha=\frac{1}{c}$, representing basal area factors 1,2 and 4. Only SDW was sampled with this method. The mean volume per area unit $(Y)$ was estimated by

$\widehat{Y}=\frac{1}{n} \sum_{i=1}^{n} \widehat{Y}_{i}=\frac{1}{n} \sum_{i=1}^{n} \sum_{j=1}^{m_{i}} \frac{V_{i j}}{\pi \cdot \omega_{i j}^{2}}$

if $m_{i}$ trees, each one with a volume $V_{i j}$, are counted from the centre of plot $i$ and $\omega_{i j}=c \cdot d_{i j}$ is the radius of the inclusion circle depending on the tree $\mathrm{DBH} d_{i j}$.

\section{Variance estimation}

For Fixed Area Sampling, Line Intersect Sampling and Angle Count Sampling, the Variance of $\widehat{Y}$ was estimated using the well-known formula for the variance of the sample mean:
$\widehat{\operatorname{var}}(\widehat{Y})=\frac{1}{n \cdot(n-1)} \sum_{i=1}^{n}\left(\widehat{Y}_{i}-\widehat{Y}\right)^{2}$

For Point Transect Sampling, the variance of $\widehat{Y}$ was estimated using the delta method (Seber 1982) cited in Buckland et al. (2001, Eq. 3.70):

$\widehat{\operatorname{var}}(\widehat{Y})=\widehat{Y}^{2} \cdot\left(\frac{\widehat{\operatorname{var}}(m)}{m^{2}}+\frac{\widehat{\operatorname{var}}(\hat{h}(0))}{(\hat{h}(0))^{2}}+\frac{\widehat{\operatorname{var}}(\hat{E}(s))}{(\hat{E}(s))^{2}}\right)$

For the estimation of $\operatorname{var}(m)$, we used a model based variance estimator (Fewster et al. 2009, Eq. 25). Due to the fact that during a sampling campaign every sample plot was visited exactly once, the estimator can be simplified to:

$\widehat{\operatorname{var}}(m)=\frac{n}{n-1} \sum_{i=1}^{n}\left(m_{i}-m\right)^{2}$

Please note that in contrast to Fewster et al. (2009), we use $n$ instead of $k$ for the number of point transects and $m$ instead of $n$ for the number of observed objects, in order to keep in line with the other methods.

We used the maximum likelihood method for the estimation of $\operatorname{var}(\hat{h}(0))$. For the half-normal detection function with just one parameter $\left(\sigma^{2}\right)$, this yields (Buckland et al. 2001, Eq. 3.52):

$\widehat{\operatorname{var}}(\hat{h}(0))=\frac{1}{m \widehat{\sigma}^{4}}=\frac{(\widehat{h}(0))^{2}}{m}$

For more details, please refer to Buckland et al. (2001, Chap. 3.3).

For the estimation of $\operatorname{var}(\widehat{E}(s))$, we used the estimator of Buckland et al. (2001, Eq. 3.66)

$\widehat{\operatorname{var}}(\widehat{E}(s))=\mathrm{e}^{2(a+b)+\widehat{\operatorname{var}}(\hat{z})} \cdot\left(1+\frac{\widehat{\operatorname{var}}(\hat{z})}{2}\right) \cdot \frac{\widehat{\operatorname{var}}(\hat{z})}{m}$

with $\widehat{\operatorname{var}}(\hat{z})$ as defined in Eq. 8, when the size bias regression method was applied. Otherwise, $\operatorname{var}(\widehat{E}(s))$ was estimated by the well known formula of the sample variance (Eq. 11).

\section{Bias approximation of Angle Count Sampling results}

Angle Count Sampling assumes total visibility of objects, any violation of this assumption leads to a NondetectionBias. In order to overcome this problem, Gove et al. (2001) consider a three-person sampling team to be optimal for Angle Count Sampling of CWD, because with this crew size two persons can traverse the point in search of DW. However, for large inventories, this seems to be ineffective and cost intensive.

Our approach is to estimate the bias using information from the Point Transect Sampling data. However, because 
the true volume of SDW is unknown, we cannot assess bias and therefore refer to it as Bias approx $_{\text {. }}$

The probability $P_{a i j}$ that an object of DBH $d_{i j}$, which is supposed to be chosen by Angle Count Sampling from the centre of plot $i$ is actually detected, is estimated depending on the detection function $g(r)$ by:

$\widehat{P_{a_{i j}}}=\frac{2}{\omega_{i j}^{2}} \cdot \int_{0}^{\omega_{i j}} r \cdot \widehat{g}(r) \mathrm{d} r$

The bias-corrected estimation of the mean volume per area unit $(Y)$ is then:

$\widehat{Y}_{\text {corr }}=\frac{1}{n} \sum_{i=1}^{n} \sum_{j=1}^{m_{i}} \frac{V_{i j}}{\pi \cdot \omega_{i j}^{2} \cdot \widehat{P_{a_{i j}}}}$

and Bias $_{\text {approx }}=\widehat{Y}-\widehat{Y}_{\text {corr }}$. The resulting root mean squared error is approximated as $\mathrm{RMSE}_{\text {approx }}=\sqrt{\mathrm{SE}^{2}+\mathrm{Bias}_{\mathrm{approx}}^{2}}$. We assumed $\mathrm{RMSE}_{\text {approx }}=\mathrm{SE}$ for all other sampling techniques, because their estimators are known to be theoretically unbiased. However, it cannot be excluded that in reality, also these estimators may have a (small) bias.

Estimation of necromass and carbon storage

For every object, the tree species group and the decay class were determined using the key of Müller-Using and Bartsch (2003), which is a modification of the key of Albrecht (1990). The key differentiates between four decay classes, from just dead, with cambium still green (1) to nearly decomposed, with dissolving form (4).

The necromass of every object was estimated as the product of its volume and assumed density. The carbon fraction of a single object was assumed to be $50 \%$ of its necromass.

Most studies about DW density (e.g. Olson 1963; Harmon et al. 1986; Mackensen and Bauhus 2003; Tobin et al. 2007; Garrett et al. 2010; Olajuyigbe et al. 2011) focus on the estimation of a decay rate $k$ to predict DW density as a function of decomposition time and initial density.

However, decomposition time of the objects sampled in our study is unknown, so that instead of data about $k$, data about density variation with decay class and species are needed. Related studies are still very rare and universal validity of existing results is arguable due to small sample sizes and different provenances of the samples. MüllerUsing and Bartsch (2009) provide data for beech (Fagus sylvatica) from Central Germany, using the key of MüllerUsing and Bartsch (2003). Næsset (1999) provides data for spruce (Picea abies) from south-eastern Norway, using different keys. Paletto and Tosi (2010) provide data for seven, mainly coniferous species using the key of Tabacchi et al. (2007), which differentiates between five decay classes.
We assumed basic density (i.e. oven-dry mass divided by fresh volume) values for the species groups and decay classes (Table 1), trying to transform the different keys and average over the studies above. Obviously, this is just a very rough estimation, but (still) the only practicable way.

The necromass per area unit $(X)$ and the carbon storage per area unit $(Z)$ were estimated analogously to the volume per area unit $(Y)$.

Time study

Working time of field measurements $t$ was recorded on 64 plots in winter and 93 plots in summer for each sampling technique. These sample sizes for the time study are lower than the number of sample plots in the study, because only working times of trained sampling teams (at least 2 weeks of practical experience) were collected. A linear regression model of $t$ on the number of observations per plot was used to estimate $t$ for all plots. Travel time from plot to plot was not regarded, because our goal was to develop a sampling technique for DW that can be integrated in existing forest inventories, this means that the points have to be visited regardless of the DW sampling, so that this factor is irrelevant. Total sampling effort $T$ depends on the required sample size $n_{\text {req }}$ for obtaining a requested standard error $\mathrm{SE}_{\text {req. }} T$ is estimated as

$\widehat{T}=\hat{\bar{t}} \cdot n_{\text {req }}=\hat{\bar{t}} \cdot \frac{\mathrm{SE}_{\text {study }}^{2} \cdot \mathrm{n}_{\text {study }}}{\mathrm{SE}_{\text {req }}^{2}}$

where $\mathrm{SE}_{\text {study }}$ is the standard error from our study and $n_{\text {study }}$ is the sample size of our study.

\section{Results}

Volume estimation

\section{$C W D$}

A half-normal detection function with cosine adjustments was chosen from AIC-based model selection for Point Transect Sampling in winter as well as in summer (Eq. 19). Estimated parameters for the detection functions are given in Table 2.

Table 1 DW basic density by decay class and species group

\begin{tabular}{lll}
\hline Decay class & \multicolumn{2}{l}{ Species group } \\
\cline { 2 - 3 } & Deciduous & Coniferous \\
\hline 1 & 0.65 & 0.40 \\
2 & 0.55 & 0.40 \\
3 & 0.50 & 0.35 \\
4 & 0.25 & 0.20 \\
\hline
\end{tabular}

All values in $\mathrm{Mg} \mathrm{m}^{-3}$ 
Table 2 Parameter estimation $( \pm \mathrm{SE})$ for the detection function $g(r)$ (Eq. 19) of CWD

\begin{tabular}{llllll}
\hline Sampling campaign & \multicolumn{2}{l}{ Parameter estimation } & & \\
\cline { 2 - 6 } & $\sigma_{0}$ & $\sigma_{1}$ & $a_{2}$ & $a_{3}$ & $a_{4}$ \\
\hline Summer & $10.66( \pm 0.1868)$ & - & $0.6217( \pm 0.0470)$ & $0.0219( \pm 0.0365)$ & $0.3003( \pm 0.0429)$ \\
Winter & $12.54( \pm 0.0531)$ & $11.35( \pm 0.1077)$ & $0.4366( \pm 0.0473)$ & $0.0450( \pm 0.0373)$ & $0.1925( \pm 0.0422)$ \\
\hline
\end{tabular}

$\sigma_{0}$ is the scale parameter in the absence of a closed snow coverage, and $\sigma_{1}$ is the scale parameter in the presence of a closed snow coverage

$\widehat{g}(r) \propto \mathrm{e}^{\frac{-r^{2}}{2 \sigma^{2}}} \cdot\left(1+\sum_{j=2}^{4} a_{j} \cdot \cos \left(\frac{j \pi r}{\omega}\right)\right)$

For the estimation of $\widehat{E}(s)$, the size bias regression method was used, and parameter estimates are given in Table 3.

It can be seen (Fig. 1) that the detection probability is lowest in summer and highest in winter, when there is no snow. The effect of the snow coverage on the detection probability is smaller than that of the foliation of ground vegetation and understorey.

For a given number of sample plots, the best performance (i.e. lowest SE) can be achieved using Fixed Area Sampling in summer and Point Transect Sampling in winter. Line Intersect Sampling produces the highest SE for the data of both sampling campaigns. Mean working time per plot was lowest for Line Intersect Sampling in both sampling campaigns, and highest for Fixed Area Sampling in summer and Point Transect Sampling in winter (Table 4).

For both sampling campaigns, the necessary sampling effort for obtaining a required $\mathrm{SE}$ is lowest for Line Intersect Sampling and highest for Point Transect Sampling, and differences are more pronounced in winter. In general, the necessary sampling effort is higher in winter than in summer (Fig. 2).

\section{SDW}

A half-normal detection function without adjustment terms $g(r)=\mathrm{e}^{\frac{-r^{2}}{2 \sigma^{2}}}$ was chosen from AIC-based model selection for the Point Transect Sampling data from both sampling campaigns.

Table 3 Parameter estimation for the size bias regression function (Eqs. 6, 7) of volume of CWD

\begin{tabular}{lllll}
\hline Sampling campaign & \multicolumn{4}{l}{ Parameter estimation } \\
\cline { 2 - 5 } & $\widehat{E}_{d}(s)$ & $\widehat{E}(s)$ & $a$ & $b$ \\
\hline Summer & 0.098 & 0.074 & -2.833 & -0.284 \\
Winter & 0.132 & 0.932 & -2.497 & -0.391 \\
\hline
\end{tabular}

$\widehat{E}_{d}(s)$ and $\widehat{E}(s)$ in $\mathrm{m}^{3}$

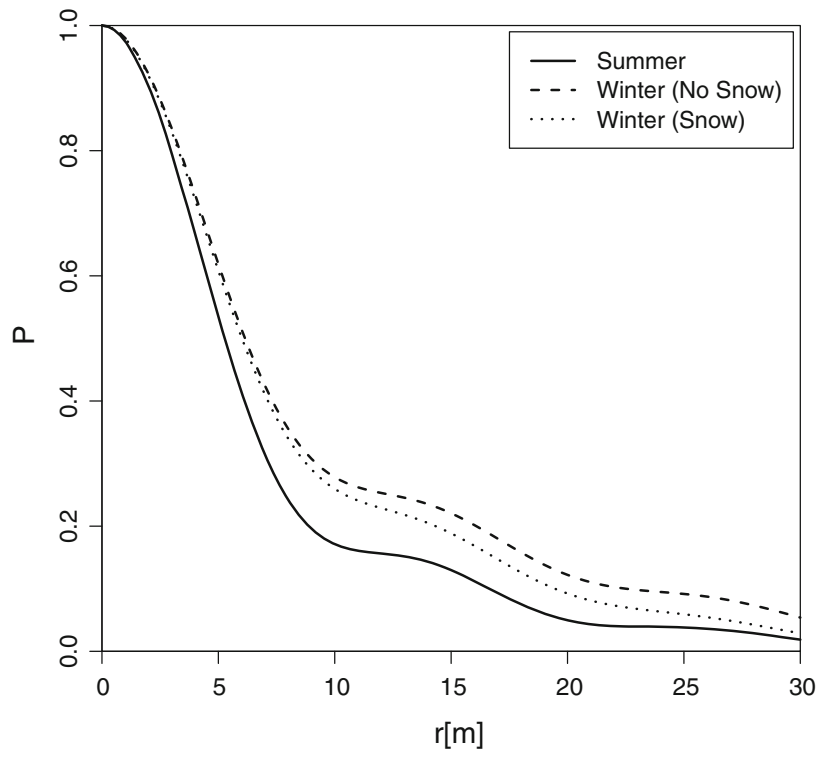

Fig. 1 Detection functions $g(r)$ (Eq. 19) of CWD

Table 4 Estimated volume of CWD per area $\widehat{Y}\left(\mathrm{~m}^{3} \mathrm{ha}^{-1}\right)$, SE of $\widehat{Y}\left(\mathrm{~m}^{3} \mathrm{ha}^{-1}\right)$ and estimated mean working time per plot $\hat{\bar{t}}(\mathrm{~s})$

\begin{tabular}{lllll}
\hline Sampling campaign & Method & $\widehat{Y}$ & $\operatorname{SE}(\widehat{Y})$ & $\hat{\bar{t}}$ \\
\hline Summer $(n=235)$ & PTS & 9.13 & 0.95 & 496 \\
& FAS & 8.19 & 0.72 & 841 \\
& LIS & 7.75 & 1.04 & 364 \\
Winter $(n=228)$ & PTS & 9.90 & 0.76 & 938 \\
& FAS & 8.00 & 0.84 & 586 \\
& LIS & 8.32 & 1.10 & 305 \\
\hline
\end{tabular}

Parameter estimates are $\sigma=12.95( \pm 0.43)$ for the summer sampling campaign and $\sigma=15.11( \pm 0.61)$ for the winter sampling campaign. The detection probability of SDW is higher in winter than in summer (Fig. 3).

For the estimation of $E(s)$, the mean size of observed clusters was used. Parameter estimates are $\widehat{E}(s)=$ $0.219 \mathrm{~m}^{3}$ for the summer campaign data and $\widehat{E}(s)=$ $0.283 \mathrm{~m}^{3}$ for the winter campaign.

For a given number of sample plots, the lowest SE can be achieved using Angle Count Sampling with basal area factor 1 for the summer sampling campaign data and using Point Transect Sampling for the winter sampling campaign data 

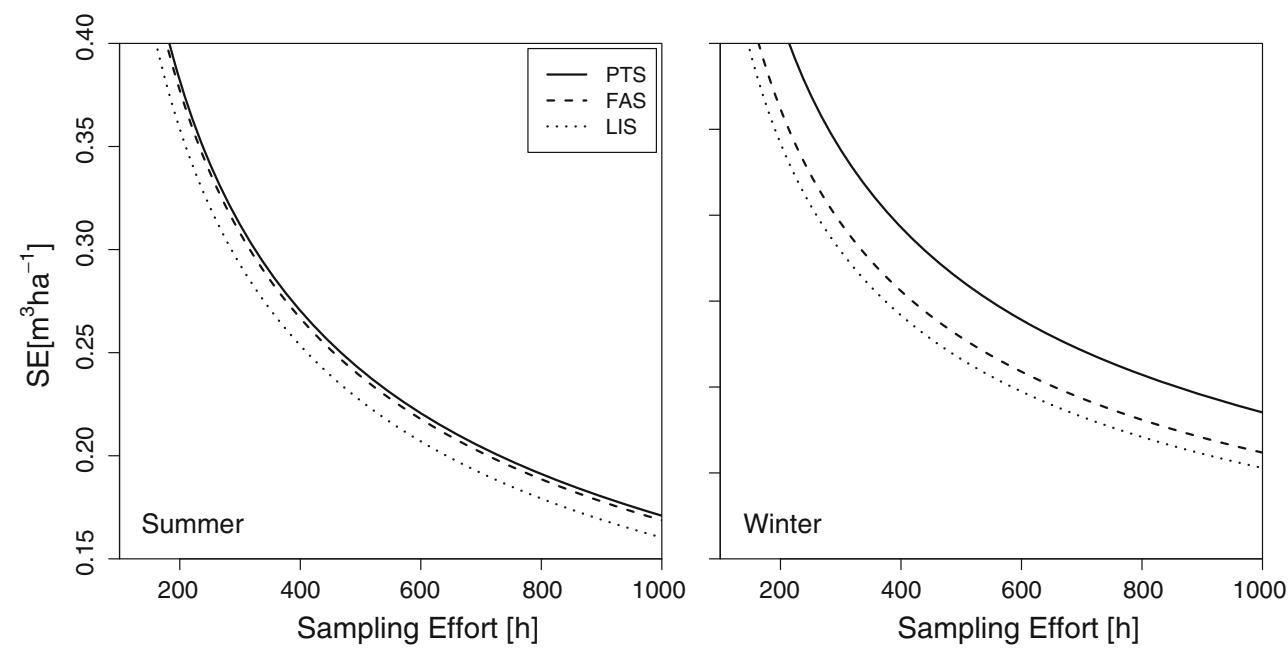

Fig. 2 Comparison of SEs of the three sampling approaches (Point Transect Sampling, Fixed Area Sampling and Line Intersect Sampling) for varying sampling efforts for the estimation of $Y$ from summer and winter sampling campaign data of CWD

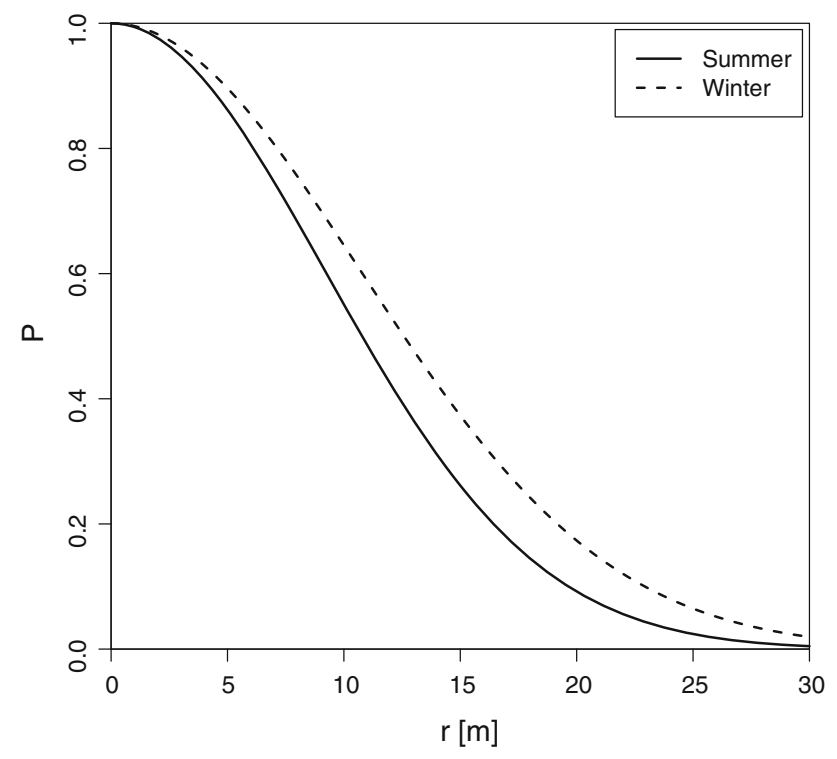

Fig. 3 Detection functions $g(r)=\mathrm{e}^{\frac{-r^{2}}{2 \sigma^{2}}}$ of SDW. Parameter estimates are $\sigma=12.95$ for summer and $\sigma=15.11$ for winter

(Table 5). However, the results strongly suggest that the Angle Count Sampling results are heavily biased: Using the bias approximation based on the Point Transect Sampling data (Eq. 17) with the estimated detection function $\widehat{g}(r)$ yields a bias-corrected volume estimation (Eq. 20).

$$
\begin{aligned}
\widehat{Y}_{\text {corr }} & =\frac{1}{n} \sum_{i=1}^{n} \sum_{j=1}^{m_{i}}\left[V_{i j} \cdot\left(2 \pi \cdot \int_{0}^{\omega_{i j}} r \cdot \mathrm{e}^{\frac{-r^{2}}{2 \sigma^{2}}} \mathrm{~d} r\right)^{-1}\right] \\
& =\frac{1}{n} \sum_{i=1}^{n} \sum_{j=1}^{m_{i}}\left[V_{i j} \cdot\left(2 \pi \cdot\left(-\mathrm{e}^{\frac{-\omega_{i j}^{2}}{2 \sigma^{2}}} \cdot \sigma^{2}+\sigma^{2}\right)\right)^{-1}\right]
\end{aligned}
$$

The bias is then estimated as Bias ${ }_{\text {approx }}=\widehat{Y}_{\text {corr }}-\widehat{Y}$ and the resulting root mean squared error $\mathrm{RMSE}_{\text {approx }}=$ $\sqrt{\mathrm{SE}^{2}+\text { Bias }_{\text {approx }}^{2}}$.

We assumed $\mathrm{RMSE}_{\text {approx }}=\mathrm{SE}$ for all other sampling techniques. It can be seen that for the data of both sampling campaigns and for a given number of sample plots the lowest RMSE $_{\text {approx }}$ can be achieved with Point Transect Sampling (Table 5). However, the working time per plot is highest for Point Transect Sampling and lowest for Angle Count Sampling with basal area factor 4 for both sampling campaigns. For the summer campaign, the necessary sampling effort for obtaining a required $\mathrm{RMSE}_{\text {approx }}$ is lowest for Point Transect Sampling and highest for Angle Count Sampling with basal area factor 1 (Fig. 4). For the winter sampling campaign, the necessary sampling effort for obtaining a required RMSE $E_{\text {approx }}$ is lowest for Angle Count Sampling with basal area factor 2, closely followed by Point Transect Sampling and highest for Angle Count Sampling with basal area factor 1 . In general, the necessary sampling effort is higher in winter than in summer (Fig. 4).

Estimation of necromass and carbon storage

Because the estimation of the detection function $g(r)$ only depends on the frequencies of clusters and distances, which remain unchanged for estimating necromass per area unit $(X)$ and carbon storage per area unit $(Z)$ rather than volume per area unit $(Y)$, the results of model selection and parameter estimation are exactly the same as those given in Results: Volume estimation.

$C W D$

Parameter estimates for the size bias regression model for the estimation of $E(s)$ are given in Table 6. Point estimates 
Table 5 Estimated volume of SDW per area $\widehat{Y}\left(\mathrm{~m}^{3} \mathrm{ha}^{-1}\right)$, estimated volume of SDW per area with applied bias-correction for angle count sampling $\widehat{Y}_{\text {corr }}\left(\mathrm{m}^{3} \mathrm{ha}^{-1}\right)$, SE of $\widehat{Y}\left(\mathrm{~m}^{3} \mathrm{ha}^{-1}\right)$, Bias approx of $\widehat{Y}\left(\mathrm{~m}^{3} \mathrm{ha}^{-1}\right), \mathrm{RMSE}_{\text {approx }}$ of $\widehat{Y}\left(\mathrm{~m}^{3} \mathrm{ha}^{-1}\right)$ and estimated mean working time per plot $\hat{\bar{t}}(\mathrm{~s})$

\begin{tabular}{|c|c|c|c|c|c|c|c|}
\hline Sampling campaign & Method & $\widehat{Y}$ & $\widehat{Y}_{\text {corr }}$ & $\operatorname{SE}(\widehat{Y})$ & $\operatorname{Bias}_{a p p r o x}(\widehat{Y})$ & $\operatorname{RMSE}_{\text {approx }}(\widehat{Y})$ & $\hat{\bar{t}}$ \\
\hline \multirow[t]{5}{*}{ Summer $(n=235)$} & PTS & 4.08 & - & 0.75 & - & 0.75 & 211 \\
\hline & FAS & 3.76 & - & 1.11 & - & 1.11 & 108 \\
\hline & ACS1 & 2.38 & 4.03 & 0.56 & -1.65 & 1.74 & 89 \\
\hline & ACS2 & 2.71 & 3.84 & 0.77 & -1.13 & 1.37 & 78 \\
\hline & ACS4 & 3.41 & 4.19 & 1.24 & -0.78 & 1.47 & 72 \\
\hline \multirow[t]{5}{*}{ Winter $(n=228)$} & PTS & 5.05 & - & 0.68 & - & 0.68 & 255 \\
\hline & FAS & 4.84 & - & 1.33 & - & 1.33 & 109 \\
\hline & ACS1 & 3.50 & 5.10 & 0.95 & -1.60 & 1.86 & 86 \\
\hline & ACS2 & 3.26 & 3.98 & 0.96 & -0.72 & 1.20 & 72 \\
\hline & ACS4 & 3.31 & 3.70 & 1.32 & -0.39 & 1.37 & 63 \\
\hline
\end{tabular}

Fig. 4 Comparison of approximated RMSEs of the different sampling approaches (Point Transect Sampling (PTS), Fixed Area Sampling (FAS) and Angle Count Sampling (ACS) with basal area factors 1,2 and 4) for varying sampling efforts for the estimation of $\widehat{Y}$ from summer and winter sampling campaign of SDW. Please note, that for the winter sampling campaign, the curves of PTS and ACS_4 cannot be discriminated
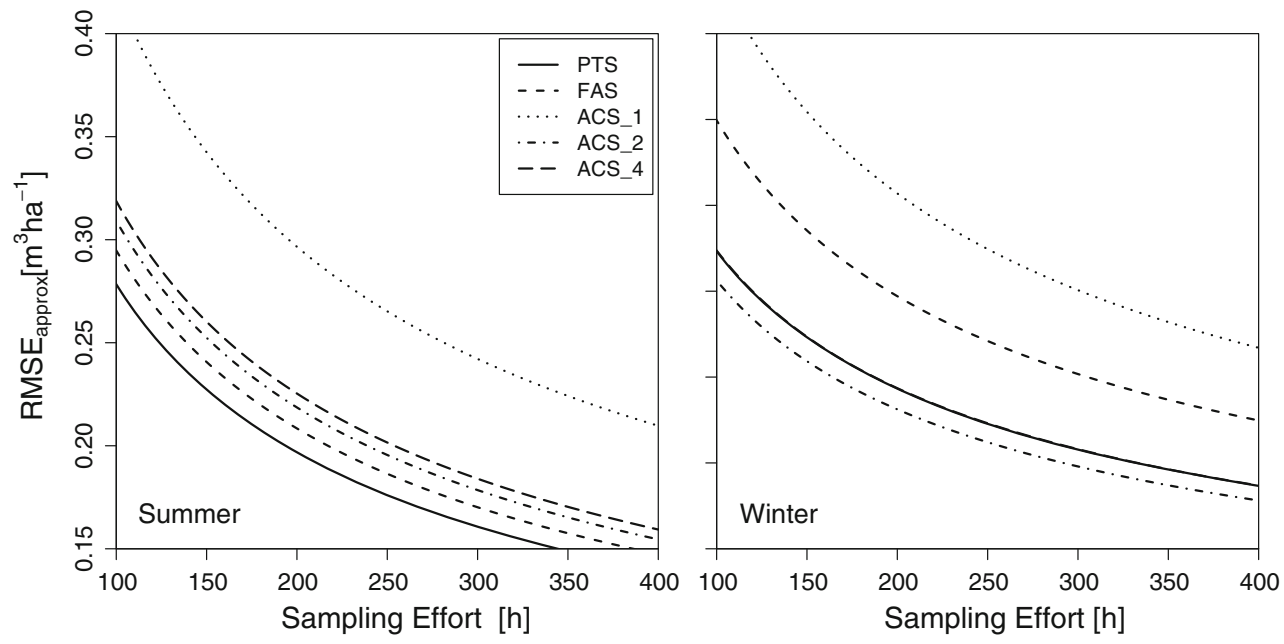

Table 6 Parameter estimation for the size bias regression function (Eqs. 6, 7) of carbon storage of CWD

\begin{tabular}{lllll}
\hline Sampling campaign & \multicolumn{5}{l}{ Parameter estimation } \\
\cline { 2 - 5 } & $\widehat{E}_{d}(s)$ & $\widehat{E}(s)$ & $a$ & $b$ \\
\hline Summer & 19.91 & 13.82 & 2.478 & -0.427 \\
Winter & 27.94 & 18.51 & 2.838 & -0.480 \\
\hline
\end{tabular}

$\widehat{E}_{d}(s)$ and $\widehat{E}(s)$ in $\mathrm{kg}$

and SEs for necromass per area $X$ and carbon storage per area $Z$ are given in Table 7 .

The ranking of the different sampling techniques is the same as for volume estimation (Results: Volume estimation): For a given number of sample plots, the best performance (i.e. lowest SE) can be achieved using Fixed Area Sampling for the summer sampling campaign data and Point
Transect Sampling for the winter data (Table 7). The necessary sampling effort for obtaining a required SE is lowest for Line Intersect Sampling for both sampling campaigns.

\section{$S D W$}

For a given number of sample plots, the lowest $\mathrm{RMSE}_{\text {approx }}$ can be achieved with Point Transect Sampling (Table 8). For the summer campaign, the necessary sampling effort

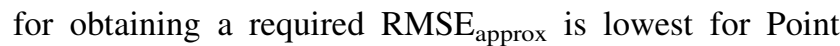
Transect Sampling and highest for Angle Count Sampling with basal area factor 1. For the winter sampling campaign, the necessary sampling effort for obtaining a required RMSE $_{\text {approx }}$ is lowest for Angle Count Sampling with basal area factor 2, closely followed by Point Transect Sampling and highest for Angle Count Sampling with basal area factor 1 . 
Table 7 Estimated necromass of CWD per area $\widehat{X}\left(\mathrm{Mg} \mathrm{ha}^{-1}\right)$, SE of $\widehat{X}\left(\mathrm{Mg} \mathrm{ha}^{-1}\right)$, estimated carbon storage in CWD per area $\widehat{Z}\left(\mathrm{Mg}\right.$ ha $\left.{ }^{-1}\right), \mathrm{SE}$ of $\widehat{Z}\left(\mathrm{Mgha}^{-1}\right)$ and estimated mean working time per plot $\hat{\bar{t}}(\mathrm{~s})$

\begin{tabular}{|c|c|c|c|c|c|c|}
\hline Sampling campaign & Method & $\widehat{X}$ & $\operatorname{SE}(\widehat{X})$ & $\widehat{Z}$ & $\operatorname{SE}(\widehat{Z})$ & $\hat{\bar{t}}$ \\
\hline \multirow[t]{3}{*}{ Summer $(n=235)$} & PTS & 3.68 & 0.39 & 1.84 & 0.19 & 496 \\
\hline & FAS & 3.14 & 0.27 & 1.57 & 0.14 & 841 \\
\hline & LIS & 2.86 & 0.40 & 1.43 & 0.20 & 305 \\
\hline \multirow[t]{3}{*}{ Winter $(n=228)$} & PTS & 3.93 & 0.31 & 1.97 & 0.15 & 938 \\
\hline & FAS & 3.46 & 0.39 & 1.73 & 0.20 & 586 \\
\hline & LIS & 3.42 & 0.48 & 1.71 & 0.24 & 364 \\
\hline
\end{tabular}

Table 8 Estimated necromass of SDW per area (with applied biascorrection for angle count sampling) $\widehat{X}_{\text {(corr) }}\left(\mathrm{Mgha}^{-1}\right)$, Bias approx of $\widehat{X}\left(\mathrm{Mg} \mathrm{ha}^{-1}\right), \mathrm{RMSE}_{\text {approx }}$ of $\widehat{X}\left(\mathrm{Mg} \mathrm{ha}^{-1}\right)$, estimated carbon storage

\begin{tabular}{llllllll}
\hline Sampling campaign & Method & $\widehat{X}_{(\text {corr })}$ & $\operatorname{Bias}_{\text {approx }}(\widehat{X})$ & $\operatorname{RMSE}_{\text {approx }}(\widehat{X})$ & $\widehat{Z}_{\text {(corr) }}$ & $\operatorname{Bias}_{\text {approx }}(\widehat{Z})$ & $\operatorname{RMSE}_{\text {approx }}(\widehat{Z})$ \\
\hline Summer $(n=235)$ & PTS & 1.95 & - & 0.35 & 0.98 & - & 0.17 \\
& FAS & 1.82 & - & 0.60 & 0.91 & - & 0.30 \\
& ACS1 & 1.96 & -0.79 & 0.84 & 0.58 & -0.39 & 0.42 \\
& ACS2 & 1.86 & -0.53 & 0.67 & 0.67 & -0.26 & 0.34 \\
Winter $(n=228)$ & ACS4 & 2.10 & -0.37 & 0.76 & 0.86 & -0.19 & 0.38 \\
& PTS & 2.54 & - & 0.36 & 1.27 & - & 0.18 \\
& FAS & 2.46 & - & 0.72 & 0.90 & -0.41 & 0.36 \\
& ACS1 & 2.62 & -0.82 & 0.98 & 0.83 & -0.18 & 0.49 \\
& ACS2 & 2.00 & -0.36 & 0.64 & 0.87 & -0.11 & 0.32 \\
\hline
\end{tabular}

of SDW per area (with applied bias-correction for angle count sampling) $\widehat{Z}_{\text {(corr) }}\left(\mathrm{Mgha}^{-1}\right)$, Bias $_{\text {approx }}$ of $\widehat{Z}\left(\mathrm{Mgha}^{-1}\right), \mathrm{RMSE}_{\text {approx }}$ of $\widehat{Z}\left(\mathrm{Mgha}^{-1}\right)$

\section{Discussion}

Materials and methods

\section{Volume estimation}

The formula of Huber (1839) is certainly not the most sophisticated method for estimating the volume of an object. However, Nagel (1999) showed that the inaccuracy of Huber's formula is about $\pm 6 \%$ for objects with a diameter of less then $40 \mathrm{~cm}$ and only $\pm 2 \%$ for larger objects. This is on par with the formula of Smalian and even better than the function of Sloboda (1985). Furthermore, Line Intersect Sampling depends on the same assumptions as Huber's formula, so that the use of this formula sets Fixed Area Sampling and Point Transect Sampling on equal terms with Line Intersect Sampling.

In a study about DW in natural forests, Meyer et al. (2003) differentiate between two types of SDW and five types of CWD and provide different cubing approaches for each type in order to minimize the error of estimating the volume of an object. This is adequate for small-scale inventories on permanent observation plots. However, it seems cost intensive and impracticable for large-scale inventories.

\section{Detection function}

There obviously is a personal influence of the observer on the detection function $g(r)$. We excluded this problem from our study: All observations were made by the first author of this paper. However, in large inventories, multiple observers are unavoidable. A methodology for incorporating multiple observers as a covariate in the model is provided in Buckland et al. (2004, Chap. 3).

\section{Size bias regression}

The bias-adjusted estimate of group size is often used even if the slope is non-significant. However, we decided not to do so, because under certain circumstances (long truncation distances), we observed a change of sign of the slope resulting in expected mean cluster size being larger than mean size of observed clusters, which obviously is an unrealistic behaviour.

\section{Decay classes}

The key of Müller-Using and Bartsch (2003) was originally developed for beech. During our fieldwork, we had no 
problems to adopt it to other species. However, the classification of objects into the four decay classes seemed somewhat problematic to us.

Meyer et al. (2009) and Kawaletz (2009) tested the reproducibility of four keys [including the one of MüllerUsing and Bartsch (2003)] with eight test people. The reproducibility of the four keys hardly differs. Between the test people, the proportion of matching is about $60 \%$ for CWD and only about $45 \%$ for SDW.

We tried to minimize this subjective effect by ensuring that the first author of this paper was attendant at every sample plot during both sampling campaigns. However, there certainly still is subjective influence on the results, which limits the reproducibility.

\section{Density estimation}

The values assumed for basic density are just very rough estimations. There, clearly, is a need for further research about density variation with decay class and species. However, the results of our study regarding the efficiency of the different sampling techniques will remain unaffected by changing densities, because all sampling techniques would be affected equally.

\section{Results}

\section{$C W D$}

Line Intersect Sampling proved to be the superior method for sampling CWD. It is also the method the sampling teams liked most, because it is easy to use and highly practicable even when there is a lot of DW at the point.

Practical problems using Point Transect Sampling occurred, when the number of visible objects was very high. In some cases, sampling effort per plot exceeded 90 min and sampling teams had to be very careful to avoid multiple counting of the same object. To overcome this problem in future inventories, it is, however, possible to shrink the truncation distance if workers are struggling with large amount of data to record.

Fixed Area Sampling proved to be especially problematic when there was snow and at points with dense ground vegetation. In order to avoid a Nondetection-Bias, the area of the sample plot has to be searched very carefully, which is timeconsuming and often frustrating for the sampling teams, especially when they have to shovel large amounts of snow.

Summarizing, we strongly recommend Line Intersect Sampling as the method of choice for sampling CWD.

\section{$S D W$}

Point Transect Sampling proved to be the most efficient method in summer, whereas in winter, Angle Count
Sampling with basal area factor 2 was slightly more efficient. However, Angle Count Sampling severely suffers from the Nondetection-Bias, which can only be corrected using ancillary data of some kind, for example, from Point Transect Sampling. In a regular inventory, these data are not available, so that the RMSE of Angle Count Sampling cannot be estimated. Furthermore, the efficiency of Angle Count Sampling strongly depends on the choice of the basal area factor, for example, in winter, Angle Count Sampling with basal area factor 2 was the most efficient method, whereas Angle Count Sampling with basal area factor 1 was the least efficient method.

Fixed Area Sampling is always less efficient than Point Transect Sampling. Using a larger caliper threshold, we expect this difference to be even more pronounced, because the number of sample plots without any object counted will increase due to the limited search area of Fixed Area Sampling.

For Point Transect Sampling, the estimated detection function $\widehat{g}(r)$ is identical for summer and winter except for the estimated scale parameter $\sigma$, hence in large inventories, where sampling lasts over a longer period, a binary covariate (foliation) indicating foliated/defoliated condition of the stand should be included in the model, so that $\sigma$ can be estimated separately for the two values of foliation.

Summarizing, we strongly recommend Point Transect Sampling as the method of choice for sampling SDW.

Acknowledgments This work was kindly funded by the German Research Foundation (Deutsche Forschungsgemeinschaft, DFG). We are grateful to the Lower-Saxony State Forests (Niedersächsische Landesforsten) for providing us forest management planning data and for the opportunity to work on their sites. We would like to thank the district forest officer Otto Beck and the forest rangers Harald Höhne and Henning Freiesleben for their hospitality and cooperativeness. We want to express our gratitude to André Hardtke, Garlef Kalberlah, Birte Krause, Lena Nothacker and Phillip Schlotzhauer for their assistance during the fieldwork. We would like to thank an anonymous reviewer for his or her thoughtful and useful comments.

Open Access This article is distributed under the terms of the Creative Commons Attribution License which permits any use, distribution, and reproduction in any medium, provided the original author(s) and the source are credited.

\section{References}

Albrecht L (1990) Grundlagen, Ziele und Methodik der waldökologischen Forschung in Naturwaldreservaten. Schriftenreihe Naturwaldreservate in Bayern, Bd 1

Bitterlich W (1952) Die Winkelzählprobe Ein optisches Messverfahren zur raschen Aufnahme besonders gearteter Probeflächen fiir die Bestimmung der Kreisflächen pro Hektar an stehenden Waldbeständen. Forstwissenschaftliches Centralblatt 71(7-8): 215-225. doi:10.1007/BF01821439

Bitterlich W (1984) The relascope idea: relative measurements in forestry. Commonwealth Agricultural Bureaux, Slough 
Böhl J, Brändli UB (2007) Deadwood volume assessment in the third Swiss National Forest Inventory: methods and first results. Eur J For Res 126(3):449-457. doi:10.1007/s10342-007-0169-3

Buckland S, Anderson D, Burnham K, Laake J, Borchers D, Thomas L (2001) Introduction to distance sampling: estimating abundance of biological populations. Oxford University Press, Oxford

Buckland S, Anderson D, Burnham K, Laake J, Borchers D, Thomas L (2004) Advanced distance sampling: estimating abundance of biological populations. Oxford University Press, Oxford

Bütler R, Schlaepfer R (2004) Wie viel Totholz braucht der Wald? Schweizerische Zeitschrift für Forstwesen 155(2):31-37

Christensen M, Hahn K, Mountford E, Òdor P, Standovár T, Rozenbergar D, Diaci J, Wijdeven S, Meyer P, Winter S, Vrska $\mathrm{T}$ (2005) Dead wood in European beech (Fagus sylvatica) forest reserves. For Ecol Manag 210:267-282. doi:10.1016/j.foreco. 2005.02.032

FAO (2006) Global forest resources assessment 2005-progress towards sustainable forest management. FAO forestry paper, vol 147. Food and Agriculture Organization of the United Nations, Rome

Fewster RM, Buckland ST, Burnham KP, Borchers DL, Jupp PE, Laake JL, Thomas L (2009) Estimating the encounter rate variance in distance sampling. Biometrics 65(1):225-236. doi:10.1111/ j.1541-0420.2008.01018.x

Garrett L, Kimberley M, Oliver G, Pearce S, Paul T (2010) Decomposition of woody debris in managed pinus radiata plantations in new zealand. For Ecol Manag. doi:10.1016/j.foreco.2010.07.041

Gauer J, Aldinger E (2005) Waldökologische Naturräume Deutschlands. Mitteilungen des Vereins für Forstliche Standortskunde und Forstpflanzenzüchtung, Freiburg

Gove J, Ducey M, Ståhl G, Ringvall A (2001) Point relascope sampling - a new way to assess downed coarse woody debris. J For 99:4-11

Harmon M, Franklin J, Swanson F, Sollins P, Gregory S, Lattin J, Anderson N, Cline S, Aumen N, Sedell J et al (1986) Ecology of coarse woody debris in temperate ecosystems. Adv Ecol Res 15(133):306. doi:10.1016/S0065-2504(08)60121-X

Huber FX (1839) Hilfs-Tafeln für Bedienstete des Forst- und Baufaches: zunächst zur leichten und schnellen Berechnung des Massengehaltes roher Holzstämme und der Theile derselben, und auch zu anderm Gebrauche für jedes landesübliche Maaß anwendbar [sic!]. Fleischmann, München

Kahl T (2008) Kohlenstofftransport aus dem Totholz in den Boden. $\mathrm{PhD}$ thesis, Fakultät für Forst- und Umweltwissenschaften der Albert-Ludwigs-Universität, Freiburg im Breisgau

Kappes H, Catalano C, Topp W (2007) Coarse woody debris ameliorates chemical and biotic soil parameters of acidified broad-leaved forests. Appl Soil Ecol 36(2-3):190-198. doi: 10.1016/j.apsoil.2007.02.003

Kawaletz H (2009) Totholzzersetzung der Buche (Fagus sylvatica L.) - Versuch einer praxistauglichen Quantifizierung des Volumenverlustes bei fortschreitender Zersetzung. Master's thesis, Fakultät für Forstwissenschaften und Waldökologie, GeorgAugust-Universität Göttingen

Kopra K, Fyles J (2005) Woody debris and nutrient cycling: Should we care??? Sustainable forest management network research note series no. 8, Edmonton

Mackensen J, Bauhus J (2003) Density loss and respiration rates in coarse woody debris of Pinus radiata, Eucalyptus regnans and Eucalyptus maculata. Soil Biol Biochem 35(1):177-186. doi: 10.1016/S0038-0717(02)00255-9

MCPFE (2002) Background information for improved Pan-European indicators for sustainable forest management. Report, Ministerial Conference on the Protection of Forests in Europe (MCPFE) Liaison Unit Vienna. http://www.foresteurope.org/filestore/
foresteurope/Meetings/2002/MCPFE_EXPERT_LEVEL_MEETING_October_Vienna_Austria/Background_info_indicators.pdf

MCPFE (2003) State of Europe's forests 2003: the MCPFE report on sustainable forest management in Europe. Report, Ministerial Conference on the Protection of Forests in Europe (MCPFE) Liaison Unit Vienna; United Nations Economic Commission for Europe/Food and Agricultural Organization (UNECE/FAO). http://www.foresteurope.org/?module=Files;action=File.getFile; $\mathrm{ID}=457$

Meyer P (1999) Totholzuntersuchungen in nordwestdeutschen Naturwäldern: Methodik und erste Ergebnisse. Forstwissenschaftliches Centralblatt 118:167-180. doi:10.1007/BF02768985

Meyer P, Bartsch N, Wolf B (2003) Methoden der Totholzerfassung im Wald. Forstarchiv 75:263-274

Meyer P, Menke N, Nagel J, Hansen J, Kawaletz H, Paar U, Evers J (2009) Entwicklung eines Managementmoduls für Totholz im Forstbetrieb. Projekt-Abschlussbericht, Deutsche Bundesstiftung Umwelt. http:// www.dbu.de/OPAC/ab/DBU-Abschlussbericht-AZ-22795.pdf

Müller-Using S, Bartsch N (2003) Totholzdynamik eines Buchenbestandes (Fagus silvatica L.) im Solling-Nachlieferung, Ursache und Zersetzung von Totholz. Allgemeine Forst und Jagdzeitung 174:122-130

Müller-Using S, Bartsch N (2009) Decay dynamic of coarse and fine woody debris of a beech (Fagus sylvatica $\mathrm{L}$.) forest in Central Germany. Eur J For Res 128(3):287-296. doi:10.1007/s10342009-0264-8

Næsset E (1999) Relationship between relative wood density of Picea abies logs and simple classification systems of decayed coarse woody debris. Scand J For Res 14(5):454-461. doi:10.1080/ 02827589950154159

Nagel J (1999) Volumenermittlung von stehendem und liegendem Totholz. In: Buchennaturwald-Reservate - unsere Urwälder von morgen, Natur- und Umweltschutz-Akademie des Landes Nordrhein-Westfalen, Recklinghausen, no. 4 in NUA Seminarberichte, pp 311-314

Neft R (2006) Bayrische Staatsforsten stellen Totholz- und Biotopbaumkonzept vor-Biotopbäume und Totholz im bayerischen Staatswald schützen, erhalten und fördern. LWF aktuell 55:28-30

Olajuyigbe S, Tobin B, Gardiner P, Nieuwenhuis M (2011) Stocks and decay dynamics of above-and belowground coarse woody debris in managed sitka spruce forests in ireland. For Ecol Manag. doi:10.1016/j.foreco.2011.06.010

Olson J (1963) Energy storage and the balance of producers and decomposers in ecological systems. Ecology 44(2):322-331. doi: $10.2307 / 1932179$

Paletto A, Tosi V (2010) Deadwood density variation with decay class in seven tree species of the italian alps. Scand J For Res 25(2):164-173. doi:10.1080/02827581003730773

Polley H (ed) (2005) Die zweite Bundeswaldinventur-BWI ${ }^{2}$-Der Inventurbericht, Bundesministerium für Ernährung, Landwirtschaft und Verbraucherschutz

R Development Core Team (2011) R: a language and environment for statistical computing. R Foundation for Statistical Computing, Vienna. http://www.R-project.org, ISBN 3-900051-07-0

Rondeux J, Sanchez C (2010) Review of indicators and field methods for monitoring biodiversity within national forest inventories. Core variable: deadwood. Environ Monit Assess 164(1-4): 617-630. doi:10.1007/s10661-009-0917-6

Saborowski J, Marx A, Nagel J, Boeckmann T (2010) Double sampling for stratification in periodic inventories-infinite population approach. For Ecol Manag 260(10):1886-1895. doi: 10.1016/j.foreco.2010.08.035

Schaber-Schoor G (2008) Wieviel Totholz braucht der Wald?Ergebnisse einer Literaturrecherche als Grundlage für ein Alt-, Totholz- und Habitatbaumkonzept. FVA-einblick 2:5-8 
Schuck A, Meyer P, Menke N, Lier M, Lindner M (2004) Forest biodiversity indicator: dead wood-a proposed approach towards operationalising the MCPFE indicator. EFI Proceedings 51:49-77

Seber G (1982) The estimation of animal abundance and related parameters. Macmillian, New York

Sloboda B (1985) Bestandesindividuelles biometrisches Schaftformmodell zur Darstellung und zum Vergleich von Formigkeit und Sortimentsausbeute sowie Inventur. In: IUFRO conference on inventorying and monitoring endagered forests, Zürich, pp 345-353

Tabacchi G, De Natale F, Floris A, Gagliano C, Gasparini P, Scrinzi G, Tosi V (2007) Italian national forest inventory: methods, state of the project, and future developments. In: Proceedings of the seventh annual forest inventory and analysis symposium, Portland, ME, USDA FS General Technical Report, vol WO77, pp 55-66

Thomas L, Buckland S, Rexstad E, Laake J, Strindberg S, Hedley S, Bishop J, Marques T, Burnham K (2010) Distance software: design and analysis of distance sampling surveys for estimating population size. J Appl Ecol 47:5-14

Tobin B, Black K, McGurdy L, Nieuwenhuis M (2007) Estimates of decay rates of components of coarse woody debris in thinned sitka spruce forests. Forestry 80(4):455

Van Wagner C (1968) The line intersect method in forest fuel sampling. For Sci 14:20-26

Warren W, Olsen P (1964) A line intersect technique for assessing logging waste. For Sci 10:267-276

Woodall C, Rondeux J, Verkerk P, Ståhl G (2009a) Estimating dead wood during national forest inventories: a review of inventory methodologies and suggestions for harmonization. Environ Manag 44(4):624-631. doi:10.1007/s00267-009-9358-9

Woodall C, Verkerk H, Rondeux J, Ståhl G (2009b) Who's counting dead wood. EFI News 17(2):12-13 